\title{
RAGAM DAN STRUKTUR BAHASA \\ PADA UPACARA ADAT RITUS TIWU PANGANTEN DI KECAMATAN BABAKAN KABUPATEN CIREBON
}

\author{
Nida Kania Dewi \\ SMK Muhammadiyah 2 Kuningan \\ Pos-el: nidakaniadewi@yahoo.co.id
}

\begin{abstract}
Abstrak
Penelitian ini bertujuan untuk mengetahui ragam dan struktur bahasa yang digunakan pada saat Upacara Adat Ritus Tiwu Panganten berlangsung. Kecamatan Babakan Kabupaten Cirebon merupakan daerah pengguna multibahasa. Dalam kesehariannya, masyarakat Babakan menggunakan bahasa Cirebon, bahasa Sunda, dan bahasa Indonesia sebagai alat komunikasinya. Masyarakat Kecamatan Babakan juga memiliki ritual upacara adat yang rutin dilaksanakan setiap tahunnya ketika musim giling tebu tiba. Upacara adat tersebut yakni Upacara Adat Ritus Tiwu Panganten. Penelitian ini bertujuan untuk mengetahui bahasa apa yang lebih sering digunakan dalam upacara adat tersebut, selain itu, struktur kata pun menjadi tujuan dari penelitian ini. Metode yang digunakan adalah metode deskriptif. Setelah dilakukan penelitian, ternyata pada upacara adat ritus tiwu panganten, bahasa yang lebih dominan digunakan adalah bahasa Sunda. Ragam bahasa yang ditemukan adalah ragam bahasa seharihari dan ragam bahasa sastra. Termasuk ragam bahasa sastra karena terdapat 'purwakanti' yang di antaranya adalah purwakanti pangluyu, purwakanti maduswara, dan purwakanti larasmadya. Struktur kata yang ditemukan adalah kata dasar, kata berimbuhan, kata ulang, kata majemuk, dan kata singkatan. Struktur kalimatnya yang dianalisis adalah kalimat konvensi atau kalimah yang mengandung subjek.
\end{abstract}

Kata Kunci: ragam bahasa, struktur bahasa, upacara adat ritus tiwu pangantén

\section{THE LANGUAGE REGISTER AND STRUCTURE IN TIWU PANGANTÉN RITES TRADITIONAL CEREMONY AT BABAKAN SUBDISTRICT OF CIREBON DISTRICT AREA}

\section{Abstract}

This research aims to determine the register and structure of the language used during the traditional ceremonies of Tiwu Panganten rites. Babakan Subdistrict of Cirebon District is an area in which multiple languages are spoken. In daily communications, people use Cirebon language, Sundanese, and Indonesian. The people of Babakan also have a traditional ceremonial ritual that is regularly held every year when the sugarcane-milling season arrives. The ceremony in question is the traditional ceremony of Tiwu Panganten rites. This study aims to determine which language is more often used in this traditional ceremony. In addition, the structure of the language is also the focus of this study. The method used is the descriptive method. Results reveal that the most dominant language used in this traditional ceremoy of Tiwu Panganten rites is Sundanese. The register found is everyday language and literatury language. Included in the literary language are 'purwakanti', among others 'purwakanti pangluyu', 'purwakanti maduswara', and 'purwakanti larasmadya'. The types of sentence structures found are 'kata dasar', 'kecap rundayan', 'kecap rajékan', 'kecap kantétan', and 'kecap wancahan'. The sentences analysed are conventional sentences or sentences containing subject.

Keywords: language register, language structure, traditional ceremony of Panganten Tiwu Rites 


\section{PENDAHULUAN}

Dalam kehidupan sehari-hari bahasa menjadi alat yang penting. Sebagai alat bahasa mempunyai fungsi tersendiri, salah satunya adalah sebagai komunikasi. Dalam penggunaanya, bahasa itu bervariatif. Begitupun dengan bahasa Sunda. Namun dalam perkembangannya, bahasa Sunda sendiri mulai diakui sebagai bahasa resmi (bukan variasi) pada tahun 1841. Dengan ditandai dengan terbitnya Kamus Bahasa Sunda pertama susunan Roorda yaitu $D e$ Nederduitsch-Maleish en Soendasch Woordenboek (Kamus Bahasa BelandaMalayu dan Sunda). Kamus ini diterbitkan di Amsterdam (Moriyama, 2013: 20).

Tapi sampai saat ini belum bisa dipastian kapan bahasa Sunda muncul. Namun lepas dari persoalan itu. Bahasa selalu berkembang dan menyesuaikan dengan zaman. Begitupun dengan keberadaan bahasa Sunda yang terus menyesuaikan. Ada beberapa yang tetap dipertahankan, semisal bahasa yang digunakan dalam sebuah ritus atau upacara suci, yang jika diganti akan menghilangkan rasa bahasa itu sendiri. Salah satu contohnya adalah penggunaan rajah dalam beberapa upacara adat.

Berdasarkan masalah di atas, di Indonesia khususnya di Jawa Barat tentu banyak ritus upacara adat yang keberadaan bahasanya masih terjaga, dalam artian tidak mengalami perubahan atau mencoba dimodernkan. Salah satu contohnya yaitu upacara adat ritus Panganten Tiwu. Yang setiap tahun dilaksanakan oleh masyarakat Kecamatan Babakan Cirebon.

Menilik pada keadaan geografis dan keadaan sosial masyarakat Sunda yang berbeda, tentu mempengaruhi pada penggunaan bahasa dari masing-masing masyarakat tersebut. Pengaruh tersebut berdampak pada munculnya berbagai variasi bahasa. Pada hakikatnya bahasa merupakan (1) suatu sistem, (2) suara atau vokal, (3) simbolis, (4) arbitrer, (5) unik, (6) suatu kebiasaan, (7) komunikatif, (8) kultural, (9) berubah, (10) bermacam- macam (Anderson, 1972:35-36),

beragam, (12) memasyarakat, dan (13) mendunia (Brown dalam Sudaryat, 2007).

Kecamatan Babakan Kabupaten Cirebon merupakan daerah yang mempunyai bahasa yang beragam. Keberagaman ini, disebabkan adanya akulturasi budaya antara Jawa dan Sunda. Sebagaimana kita ketahui, bahwa Kabupaten Cirebon secara wilayah merupakan wilayah Jawa Barat, tetapi secara penggunaan bahasa bukan Sunda, tapi Jawa. Selain itu keberadaan geografi Kabupaten Cirebon yang dekat dengan Kuningan dan Majalengka, yang notabene kedua kabupaten ini masarakat pengguna bahasanya adalah Sunda. Ini yang kemudian menyebabkan akulturasi, dan akulturasi ini kebanyakan terjadi di beberapa wilayah Cirebon yang dekat dengan Kuningan atau Majalengka. Seperti yang terjadi di Kecamatan Babakan.

Umumnya masyarakat di Kecamatan Babakan, menggunakan dua bahasa yaitu bahasa Sunda dan Jawa. Dalam arti lain masyarakat penutur yang ada di kecamatan ini menggunakan kedwibahasaan. Secara harfiah bilingulisme adalah penggunaan dua bahasa atau kode basa. Secara sosiolinguistik bilingualisme diartikan penggunaan dua bahasa oleh satu orang penutur dalam bergaul dengan manusia lainnya secara bergantian (Mackey dalam Chaer dan Agustina, 2010:84).

Dalam upacara adat ritus Tiwu Panganten digunakan sekurang-kurangnya ada tiga bahasa yang digunakan yaitu bahasa Sunda, Cirebon, dan Indonesia. Bagaimana ketiga bahasa itu digunakan baik ragam bahasanya baik strukturya. Hal ini kemudian menjadi pertanyaan selanjutnya. Dan tulisan ini dimaksudkan untuk menjawab pertanyaan tersebut.

\section{METODE}

Metode yang digunakan dalam penelitian ini adalah metode deskriptif (memaparkan) kualitatif. Metode deskriptif yaitu metode yang digunakan untuk 
mendeskripsikan dan menjelaskan kejadiankejadian yang berlangsung dalam masa lampau (Sudjana, 1987:52). Menurut Surakhmad (1989:39), metode deskriptif yaitu metode yang digunakan untuk memecahkan masalah dan menyelesaikan persoalan-persoalan dengan cara mengumpulan data, menyusun pembagian, menganalisis dan menafsirkan data. Dalam penelitian ini, yang dideskripsikan itu ketika yang digunakan dalam upacara adat ritus Tiwu Panganten dilihat dari kajian ragam bahasa, kosa kata, alih kode, dan tatakrama bahasa.

\section{HASIL DAN PEMBAHASAN}

Dalam pelaksanaan UARTP, ternyata ada tiga bahasa yang digunakan yaitu bahasa Indonesia yang kebanyakan sebatas pengantar, bahasa Sunda yang datanya memang lebih dominan dan kebanyakan bahasa Sunda yang digunakan sebagai bahasa sastra, dan bahasa Cirebon terlihat datanya hanya sedikit digunakan dalam konteks sastra.

\section{Struktur Kata dalam UARTP}

Dari data UARTP terdapat berbai ragam bahasa Sunda sehari-hari dan ragam bahasa Sunda sastra, baik dalam kata dasar baik dalam kata jamak yang mencakup, kata berimbuhan, kata ulang, kata majemuk, dan kata singkatan.

\section{Kata Dasar}

Kata dasar dalam UARTP merupakan kata yang dibentuk oleh satu morfem bebas. Dari hasil analisis data terdapat 208 kata dasar. Berdasarkan jumlah suku kata, kata dasar dalam UARTP dapat dibagi menjadi empat bagian yaitu kata dasar satu suku kata, kata dasar dua suku kata, kata dasar tiga suku kata, dan kata dasar empat suku kata.

a) Kata Dasar Satu Suku Kata.

Dilihat dari polanya, kata dasar satu suku kata memiliki pola sebagai berikut.

- Pola a.1: KV

Contoh: (1) $d a$ (UARTP/pa14/4),
(2) gé (UARTP/pa43/j6).

- Pola a.2: KVK Contoh: (1) cag (UARTP/pa11/j4)

(2) duh (UARTP/pa9/j10), (UARTP/pa36/j3)

- Pola a.3: KKVK Contoh: (1) bral (UARTP/pa10/j7), (UARTP/pa28/2)

- Pola a.4: KVKK

Contoh: (1) jeung (UARTP/pa9/j1), (UARTP/pa10/j6), (UARTP/pa28/j2), (UARTP/pa33/j1), (2) ping (UARTP/pa39/j2)

- Pola a.5: KVVK Contoh: (1) keur (UARTP/pa30/j1)

b) Kata Dasar Dua Suku Kata

Dilihat dari polanya, kata dasar dua suku kata memiliki pola sebagai berikut.

- Pola b.1: VV

іеи (UARTP/pa9/j12),

(UARTP/pa11/j4), (UARTP/pa21/j3),

(UARTP/pa21/j5), (UARTP/pa24/j5),

(UARTP/pa24/j7), (UARTP/pa25/j8), (UARTP/pa37/j5), (UARTP/pa39/j1)

- Pola b.2: KVV діеи (UARTP/pa9/j3), (UARTP/pa9/j5)

Mei (UARTP/pa39/j2)

- Pola b.3: VKV aki (UARTP/p11/j4), (UARTP/pa33/j1) ati (UARTP/pa20/j6)

- Pola b.4: VKVK abdi (UARTP/pa39/j5) agung (UARTP/pa22/j1), (UARTP/pa34/j1), (UARTP/pa40/j1)

- Pola b.5: kvkv badé (UARTP/pa35/j3) bagi (UARTP/pa42/j3)

- Pola b.6: VKKV asma (UARTP/pa39/j3)

- Pola b.7: KVVK juang (UARTP/pa20/j1) taun (UARTP/pa21/j5), (UARTP/pa24/j7), (UARTP/pa25/j8), (UARTP/pa25/j9), (UARTP/pa39/j1)

- Pola b.8: KVKVK bangun (UARTP/pa15/j5) baris (UARTP/pa25/j7, (UARTP/pa30/j6) 
- Pola b.9: vkkvk anjeun (UARTP/pa6/j2), (UARTP/pa7/j2), (UARTP/pa10/j4) ikhlas (UARTP/pa31/j3)

- Pola b.10: KVKVV balai (UARTP/pa43/j4) bukti (UARTP/pa25/j1)

- Pola b.11: KVKKVK berkah (UARTP/pa36/j6) cunduk (UARTP/pa15/j1), (UARTP/pa26/j1)

c) Kata Dasar Tiga Suku Kata Dilihat dari polanya, kata dasar tiga suku kata memiliki pola sebagai berikut.

- Pola c.1: VKVKV ayeuna (UARTP/pa9/j6), (UARTP/pa35/j2), (UARTP/pa36/j1)

- Pola c.2: KVKVV bagéa (UARTP/pa40/j1), (UARTP/pa41/j1) daria (UARTP/pa10/j3)

- Pola c.3: KVVKV buana (UARTP/pa18/j3) tiasa (UARTP/pa38/j2)

- Pola c.4: VKVKVK ibarat (UARTP/pa11/j3)

- Pola c.5: KVKVKV balaka (UARTP/pa11/j3) budaya (UARTP/pa11/j4)

- Pola c.6: KVKVVK palias (UARTP/pa14/j1), (UARTP/pa14/j2)

- Pola c.7: KVKKVV satria (UARTP/pa20/j2)

- Pola c.8: KVKVKVK babakan (UARTP/pa32/j3), (UARTP/pa32/j4) makalang (UARTP/pa18/j3)

- Pola c.9: KVKKVKV peryogi (UARTP/pa42/j5) ponggawa (UARTP/pa15/j3), (UARTP/pa20/j1), (UARTP/pa20/j3), (UARTP/pa33/j4), (UARTP/pa33/j6)

- Pola c.10: KVKVKKV towéksa (UARTP/pa10/j7)

- Pola c. 11: KVKVKKVK bayuhyuh (UARTP/pa20/j3) hapunten (UARTP/pa37/j6)
- Pola c.12: KVKKVKVK karyawan (UARTP/pa25/j10), (UARTP/pa42/j1), (UARTP/pa43/j5) munggaran (UARTP/pa30/j6)

- Pola c.13: KVKKVKKVK perténtang (UARTP/pa15/j4), (UARTP/pa18/j2), (UARTP/pa20/j5), (UARTP/pa33/j3), (UARTP/pa33/j5)

- Pola c.14: KKVKVKKV produksi (UARTP/pa25/j8), (UARTP/pa25/j10), (UARTP/pa42/j4)

d) Kata Dasar Empat Suku Kata Dilihat dari polanya, kata dasar empat suku kata memilik pola sebagai berikut.

- Pola d.1: VKVKVKV upacara (UARTP/pa9/j3), (UARTP/pa9/j5), (UARTP/pa32/j1)

- Pola d.2: KVKVKVV panitia (UARTP/pa32/j5)

- Pola d.3: KVKVKVKV bidadari (UARTP/pa24/j4)

- Pola d.4: KVKVVKKV pamiarsa (UARTP/pa5/j1), (UARTP/pa24/j1)

\section{Kata Berimbuhan}

Dalam UARTP terdapat afiksasi atau kata berimbuhan. Dari hasil analisis data terdapat 121 afiksasi yang terbagi menjadi lima, yaitu: prefiks, infiks, sufiks, konfiks, dan ambifiks.

1) Prefiks

Prefiks yang terdapat dalam UARTP memililiki pola seperti:

- Pola a.1: di- + KD diaping (UARTP/pa34/j4)

aping + di- $\rightarrow$ diaping

- Pola a.2: $k a-+\mathrm{KD}$ karingrang (UARTP/pa15/j5) ringrang $+k a-\rightarrow$ karingrang

- Pola a.3: N- + KD majar (UARTP/pa11/j2), (UARTP/pa14/j4) pajar + (nasal- $) \rightarrow$ majar

- Pola a.4: mang- + KD mangrupi(a) (UARTP/pa22/j4), (UARTP/pa24/j3), (UARTP/pa25/j1), (UARTP/pa32/j2) 
rupa + mang- $\rightarrow$ mangrupa

- Pola a.5: $n g a-+\mathrm{KD}$ ngabéla (UARTP/pa20/j7)

béla + nga- $\rightarrow$ ngabéla

- Pola a.6: pang- + KD pangagung (UARTP/pa34/j2) agung + pa- + ng- $\rightarrow$ pangagung

- Pola a.7: $p a-+\mathrm{KD}$ panuhun (UARTP/pa38/j1),

(UARTP/pa42/j1) nuhun + pa- $\rightarrow$ panuhun

- Pola a.8: pi- + KD pituduh (UARTP/pa6/j2) tuduh + pi- $\rightarrow$ pituduh

- Pola a.9: sa- + KD sakadar (UARTP/pa14/j4)

kadar + sa- $\rightarrow$ sakadar

2) Infiks

Infiks yang terdapat dalam UARTP memililiki pola seperti:

- Pola b.1: -ar- + KD garandang (UARTP/pa27/j4) gandang + -ar- $\rightarrow$ garandang

- Pola b.2: -in- + KD rinéka (UARTP/pa32/j2) réka + -in- $\rightarrow$ rinéka

- Pola b.3: -um- + KD dumasar (UARTP/pa25/j3) dasar + -um- $\rightarrow$ dumasar

3) Sufiks

Sufiks yang terdapat dalam UARTP memililiki pola seperti:

- Pola c.1:-an + KD atikan (UARTP/pa13/j3) atik + -an $\rightarrow$ atikan

- Pola c.2: -keun + KD cegahing (UARTP/pa8/j4) cegah + -ing $\rightarrow$ cegahing

- Pola c.3: -keun + KD bagéakeun (UARTP/pa5/j2) bagéa + -keun $\rightarrow$ bagéakeun

- Pola c4: $-n a+\mathrm{KD}$ ahlina (UARTP/pa38/j5)

ahli $+-n a \rightarrow$ ahlina

4) Konfiks

Konfiks yang terdapat dalam UARTP memililiki pola seperti:
- Pola d.1: $k a-+\mathrm{KD}+-a n$ kagampilan (UARTP/pa6/j3), (UARTP/pa7/j3) gampil + ka-an $\rightarrow$ kagampilan

- Pola d.2: $p a-+\mathrm{KD}+-a n$ pagelaran (UARTP/pa21/j3) gelar + pa-an $\rightarrow$ pagelaran

- Pola d.3: $s a-+\mathrm{KD}+-a n$ sauyunan (UARTP/pa25/j4) uyun + sa- + -an $\rightarrow$ sauyunan

5) Ambifiks

Ambifiks yang terdapat dalam UARTP memililiki pola seperti:

- Pola e.1: $d i-$ + KD + -an dipayungan (UARTP/pa34/j1) payung + di- + -an $\rightarrow$ dipayungan

- Pola e.2: di- + KD + -na diiringna (UARTP/pa30/j4) iring + di $-+-n a \rightarrow$ diiringna

- Pola e.3: $k a-+\mathrm{KD}+-a n$ kakiatan (UARTP/pa6/j3), (UARTP/pa7/j3)

kiat + ka- + -an $\rightarrow$ kakiatan

- Pola e.4: $N$ - +-an + KD manggihan (UARTP/pa23/j2) panggih + nasal- + -an $\rightarrow$ manggihan

- Pola e.5: $\mathrm{N}-$ + KD + -keun ngadongkapkeun (UARTP/pa25/j9) dongkap $+n g a-+-k e u n \rightarrow$ ngadongkapkeun

- Pola e.6: $n g a-+-a m-+K D$ ngamalir (UARTP/pa12/j1) alir + nga- + -am- $\rightarrow$ ngamalir

- Pola e.7: nga- + KD + -an ngawalan (UARTP/pa41/j6) awal +ng- + -an $\rightarrow$ ngawalan

- Pola e.8: $n g a-+\mathrm{KD}+-n a$ ngapitna (UARTP/pa29/j6) apit $+n g-+-n a \rightarrow$ ngapitna

- Pola e.9: $N$ - + KD + -keun nguniangkeun (UARTP/pa7/j2) kuniang + ng- + -keun $\rightarrow$ nguniangkeun

- Pola e.10: $N-+\mathrm{KD}+-a n$ nyaksénan (UARTP/pa9/j11), (UARTP/pa40/j6) saksi + ny- + -an $\rightarrow$ nyaksénan

- Pola e.11: $p a-+N-+\mathrm{KD}+-a n$ pamasrahan (UARTP/pa9/j12), (UARTP/pa35/j3) 
pasrah + pa- + nasal- $+-a n \rightarrow$ pamasrahan

- Pola e.12: $p a-+\mathrm{N}-+\mathrm{KD}+-a n$ pangiringna (UARTP/pa25/j6)

iring $+p a-+n g-+-n a \rightarrow$ pangiringna

- Pola e.13: $s a-+\mathrm{KD}+-a n+-e u n$ sapulukaneun (UARTP/pa8/j5)

puluk + sa- + -an + -eun $\rightarrow$ sapulukaneun

\section{Kata Ulang}

Dalam UARTP terdapat kata ulang murni (Rm), kata ulang sebagian (Rs), kata ulang dwimadya (Rdmy), dan kata ulang berimbuhan.

1) Kata ulang murni

Pola a.1: KA + Rm

2) Kata ulang sebagian

Polanya b.1: KD + Rs

3) Kata ulang dwimadya

Polanya c. $1:$ KD + Rdmy.

4) Kata ulang berimbuhan

- Pola d.1: di- + Rm dianti-anti (UARTP/pa40/j2), (UARTP/pa41/j2)

- Pola d.2: $n g a-+\mathrm{Rm}$ ngareuah-reuah (UARTP/pa24/j6)

- Pola d.3: Rm + -na sobat-sobatna (UARTP/pa38/j5)

- Pola d.4: Rs + -an wawanén (UARTP/pa20/j4)

\section{Kata Majemuk}

Dalam UARTP terdapat beberapa kata majemuk berdasarkan pola:

- Pola a: KK: KB + KB abdi dalem (UARTP/pa8/j5)

- Pola b: KK: KB + KS kaula muda (UARTP/pa18/j2)

- Pola c: KK: KP + KP gotong royong (UARTP/pa25/j3)

- Pola d: KK: KS + KS hadé rupa (UARTP/pa29/j4)

- Pola e: KK: KS + KB hadé basa (UARTP/pa29/j4)

- Pola f: KK: KBil + KBil dua welas (UARTP/pa24/j2)

- Pola g: KK: KBil + KB para pamimpin (UARTP/pa42/j2)

- Pola h: KK: KBil + KS

trisatya (UARTP/pa22/j1)

6. Kata Singkatan

Dalam UARTP terdapat empat kata singkatan, yaitu:

1) Kata Tingkesan (akronim)

pola KW: eng1 + eng2.

jasprona (UARTP/pa42/j3)

jasprona $\leftarrow$ jasa produksi $+-n a$

2) Kata Singgetan

pola $\mathrm{KW}: \mathrm{H} 1+\mathrm{H} 1+\mathrm{H} 1$.

SMA (UARTP/pa32/j3),

(UARTP/pa32/j4)

SMA $\leftarrow$ Sekolah Menengah Atas

3) Kata Tangkesan (Haplologi)

pola $\mathrm{KW}: \mathrm{H} 1+\mathrm{Kc}$.

taya (UARTP/pa15/j5)

taya $\leftarrow$ teu aya

\section{Struktur Kalimat dalam UARTP}

Dalam data UARTP terdapat berbagai kalimat dalam ragam bahasa Sunda seharihari dan juga ragam bahasa Sunda sastra, baik kalimat tunggal baik kalimah jamak. Dari hasil analisis data, struktur kalimat dalam data UARTP dapat dijelaskan di bawah ini.

\section{Struktur Kalimat Tunggal}

Struktur Kalimat tunggal dalam UARTP data dibagi menjadi empat pola kalimat.

a. Pola 1: KTgl $\rightarrow \mathrm{S}-\mathrm{P}$

Paman léngsér geura luluguhan!

(UARTP/p5/j5)

b. Pola 2: KTgl $\rightarrow$ S-P-O

Jawara! Geura amit ka pamingpin pabrik (UARTP/p6/j5)

c. Pola 3: KTgl $\rightarrow$ S-P-Pel

Sareng mugi Allah maparin kakiatan kagampilan (UARTP/p7/j3)

d. Pola 4: KTgl $\rightarrow$ S-P-K

Mugi anjeun maparin pituduh anu leres mémang leres... (UARTP/p6/j2)

Dalam analisis data di atas ternyata bahasa yang digunakan dalam UARTP adalah tiga bahasa Indonesia (BI), bahasa 
Cirebon (BC), dan bahasa Sunda (BS). BS lebih dominan digunakan daripada BI dan BC. BI digunakan hanya sebatas pengantar. BC hanya sedikit yang digunakan dalam ragam basa sastra, padahal mayoritas masyarakat Babakan menggunakan BC.

Ragam bahasa yang terdapat yaitu ragam bahasa sehari-hari dan ragam basa sastra. Disebut ragam bahasa sastra sebab mengandung unsur sastra di antaranya purwakanti. Struktur kata yang terdapat yaitu kata dasar, kata berimbuhan, kata ulang, kata majemuk, dan kata singkatan. Dan struktur kata yang dianalisis yaitu kalimat konvensi atau kalimat yang mengandung subjek, yang dalam data terdapat 24 kalimah konvensi. Pola kalimat yang paling banyak digunakan adalah pola kalimat $\mathrm{KTgl} \rightarrow \mathrm{S}-\mathrm{P}$ atau kalimat tunggal $\rightarrow$ Subjek-Predikat.

Berdasarkan hasil analisis data dalam UARTP, terdapat frekuensi data ragam bahasa seperti pada tabel 1 .

\section{Tabel 1 Frekuensi Data Ragam Bahasa}

\begin{tabular}{ccccc}
\hline No. & $\begin{array}{c}\text { Bahasa yang } \\
\text { digunakan }\end{array}$ & Jumlah & $\%$ & F \\
\hline 1. & BI & 11 & 22,4 & 49 \\
\hline 2. & BS & 36 & 73,4 & 49 \\
\hline 3. & BC & 2 & 4,0 & 49 \\
\hline
\end{tabular}

Hasil analisis data struktur kata dalam pelaksanaan UARTP terdapat dalam tabel 2 berikut.

\section{Tabel 2 Struktur Kata}

\begin{tabular}{clccc}
\hline No. & Bentuk Kata & Jmlh & $\mathbf{\%}$ & $\mathbf{F}$ \\
\hline 1. & Kata dasar & 208 & 57,3 & 363 \\
\hline 2. & Kata & 121 & 33,3 & 363 \\
& Berimbuhan & & & \\
\hline 3. & Kata Ulang & 13 & 3,5 & 363 \\
\hline 4. & Kata Majemuk & 17 & 4,6 & 363 \\
\hline 5. & Kata Singkatan & 4 & 1,1 & 363 \\
\hline
\end{tabular}

Hasil analisis data struktur kalimat dalam pelaksanaan UARTP terdapat dalam tabel di bawah.
Tabel 3 Struktur Kalimat

\begin{tabular}{clccc}
\hline No. & \multicolumn{1}{c}{ Pola Kalimah } & Jml & \% & F \\
\hline 1. & $\begin{array}{l}\text { Pola 1: KTgl } \rightarrow \\
\text { S-P }\end{array}$ & 12 & 50 & 24 \\
\hline 2. & $\begin{array}{l}\text { Pola 2: KTgl } \rightarrow \\
\text { S-P-O }\end{array}$ & 8 & 33,3 & 24 \\
\hline 3. & $\begin{array}{l}\text { Pola 3: KTgl } \rightarrow \\
\text { S-P-Pelengkap }\end{array}$ & 1 & 4,1 & 24 \\
\hline 4. & $\begin{array}{l}\text { Pola 4: KTgl } \rightarrow \\
\text { S-P-K }\end{array}$ & 3 & 12,5 & 24 \\
\hline
\end{tabular}

\section{SIMPULAN}

Dalam pelaksanaan UARTP, ternyata ada tiga bahasa yang digunakan yaitu bahasa Indonesia yang kebanyakan sebatas pengantar, kedua bahasa Sunda yang datanya memang lebih dominan dan kebanyakan bahasa Sunda yang digunakan sebagai bahasa sastra, sedangkan basa Cirebon terlihat datanya hanya sedikit digunakan dalam konteks sastra.

Struktur bahasa yang mencakup struktur kata dan struktur kalimat. Struktur kata dalam pelaksanaan UARTP mencakup kata dasar, kata berimbuhan, kata ulang, kata majemuk, dan kata singkatan. Terkuak dalam data, kebanyakan kata yang dgunakan dalam UARTP yaitu kata dasar, jumlahnya ada 208 kata, kata berimbuhan jumlahnya ada 121 kata, kata ulang jumlahnya 13 kata, kata majemuk ada 17 kata, dan yang paling sedikit yaitu kata singkatan empat kata. Dalam analisis struktur kata terdapat pola-pola kata yang di antaranya, untuk kata dasar satu suku kata ada pola (a.1) KV, (a.2) KVK, (a.3) KKVK, (a.4) KVKK, (a.5) KVVK, kata salancar dua suku kata ada pola (b.1) VV, (b.2) KVV, (b.3) VKV, (b.4) VKVK, (b.5) kvkv, (b.6) VKKV, (b.7) KVVK, (b.8) KVKVK, (b.9) vkkvk, (b.10) KVKVV, (b.11) KVKKVK, untuk kata dasar tiga suku kata ada pola (c.1) VKVKV, (c.2) KVKVV, (c.3) KVVKV, (c.4) VKVKVK, (c.5) KVKVKV, (c.6) KVKVVK, (c.7) KVKKVV, (c.8) KVKVKVK, (c.9) KVKKVKV, (c.10) KVKVKKV, (c.11) KVKVKKVK, (c.12) KVKKVKVK, (c.13) 
KVKKVKKVK, dan (c.14) KKVKVKKV, untuk kata dasar empat suku kata ada pola (d.1) VKVKVKV, (d.2) KVKVKVV, (d.3) KVKVKVKV, dan (d.4) KVKVVKKV.

Pola-pola yang tergambar dalam kata berimbuhan yaitu untuk kata berimbuhan diberi awalan yaitu pola (a.1) $d i-$ + KA, (a.2) $k a-+\mathrm{KA},($ a.3) $\mathrm{N}-$ + KA, (a.4) mang+ KA, (a.5) nga- + KA, (a.6) pang- + KA, (a.7) $p a-+\mathrm{KA},\left(\right.$ a.8) $p i-+\mathrm{KA}$, (a.9) $s a^{-}+$ KA. Pola yang ada dalam kata berimbuhan imbuhan tengah yaitu (b.1) -ar- + KA, (b.2) -in- + KA, (b.3) -um- + KA, untuk pola kata berimbuhan imbuhan tengah yaitu (c.1) -an + KA, (c.2) -keun + KA, (c.3) -keun + KA, (c4) $-n a+\mathrm{KA}$, untuk kata berimbuhan imbuhan awalan-akhir yaitu (d.1) $k a-+\mathrm{KA}$ $+-a n,(\mathrm{~d} .2) p a-+\mathrm{KA}+-a n,(\mathrm{~d} .3) s a-+\mathrm{KA}$ $+-a n$, untuk kata berimbuhan konfiks yaitu (e.1) $d i-$ + KA + -an, (e.2) $d i-$ + KA + -na, (e.3) $k a-+\mathrm{KA}+-a n,(\mathrm{e} .4) k a-+\mathrm{KA}+-a n$, (e.5) $n g a-+\mathrm{KA}+-k e u n,(\mathrm{e} .6) n g a-+-a m-$ $+\mathrm{KA},(\mathrm{e} .7) n g a-+\mathrm{KA}-a n,(\mathrm{e} .8) n g a-+\mathrm{KA}$ $+-n a,(\mathrm{e} .9) \mathrm{N}-+\mathrm{KA}+-k e u n,(\mathrm{e} .10) \mathrm{N}-+$ $\mathrm{KA}+-a n,(\mathrm{e} .11) p a-+\mathrm{N}-+\mathrm{KA}+-a n$, (e.12) $p a-+\mathrm{N}-+\mathrm{KA}+-a n,(\mathrm{e} .13) s a-+$ $\mathrm{KA}+-a n+-e u n$.

Pola-pola yang tergali dalam kata ulang yaitu (a.1) KA + Rm untuk kata ulang murni, (b.1) KA + Rs untuk kata ulang sebagian, (c.1) KA + Rdmy untuk kata ulang dwimadya, (d.1) di- + Rm, (d.2) nga+ Rm, (d.3) Rm + -na, (d.4) Rs + -an. Sedangkan dalam kata majemuk pola-pola yang terkuak yaitu pola (a) KK: KB + KB, b: KK: KB + KS, (c) KK: KP + KP, (d) $\mathrm{KK}: \mathrm{KS}+\mathrm{KS}$, (e) KK: KS + KB, (f) KK: KBil + KBil, (g) KK: ta KBil + KB, (h) $\mathrm{KK}: \mathrm{KBil}+\mathrm{KS}$.
Dalam kata singkatan, -pola segi ieu, pola KW: eng1 + eng2 untuk ktingkesan, pola $\mathrm{KW}: \mathrm{H} 1+\mathrm{H} 1+\mathrm{H} 1$ untuk kata singkatan, pola KW: H1 + Kc untuk kata ringkasan. Struktur kalimatnya meliputi kalimat konvensi kebanyakan merupakan kalimat tunggal pola KTgl $\rightarrow$ S-P.

Kecamatan Babakan Kabupaten Cirebon adalah salah satu daerah yang berada di wilayah Jawa Barat. Wilayah yang umumnya menggunakan bahasa Sunda, tapi untuk wilayah Cirebon bahasa yang digunakan adalah bahasa Cirebon yang lebih mirip dengan bahasa Jawa.

\section{PUSTAKA RUJUKAN}

Chaer, A. dan Agustina, L. (2010). Sosiolinguistik Perkenalan Awal. Jakarta: PT. Rineka Cipta.

Moriyama, M. (2013). Semangat Baru: Kolonialisme, Budaya Cetak, dan Kesusastraan Sunda abad ke-19 edisi revisi. Jogja: Komunitas Bambu.

Sudaryat, Yayat, spk. 2007. Tata Basa Sunda Kiwari. Bandung: Yrama Widya.

Surakhmad, W. (2004). Pengantar Penelitian Ilmiah. Bandung : Tarsito

\section{UCAPAN TERIMA KASIH}

Terima kasih kepada semua pihak yang telah membantu penelitian ini, terutama kepada Bapak dan Ibu Dosen di Prodi Bahasa dan Budaya Sunda SPs UPI. Penulis pun mengucapkan terima kasih kepada Penyunting Jurnal Lokabasa yang telah berkenan memuat tulisan ini. 